\title{
Aspectos Qualitativos de Águas de Lagoas Costeiras e seus Fatores Influentes - Estudo de Caso: Lagoa MÃE-BÁ, Espírito Santo
}

\author{
Adriana Alves Pereira, Antônio Sérgio Ferreira Mendonça \\ Universidade Federal do Espírito Santo - adri.a.p@terra.com.br \\ Mário de Castro Andrade Filho \\ Universidade Federal do Ceará
}

Recebido: 30/03/04 revisado: -/-/- aceito: 20/10/05

\section{RESUMO}

Lagoas costeiras ocupam cerca de $13 \%$ da costa mundial, são ambientes rasos, altamente produtivos e submetidos a influências continentais e marinhas. Os usos múltiplos de suas águas e atividades antrópicas realizadas em suas bacias hidrográficas têm causado significativas alterações na qualidade de seus recursos hidricos. Objetiva-se, através de dados da lagoa Mãe-Bá, situada no litoral sul do Estado do Espírito Santo, contribuir para um maior conhecimento a respeito das influências de aspectos naturais e antrópicos sobre parâmetros de qualidade de águas de lagoas costeiras e das interações entre as diversas variáveis ambientais, além da caracterização do grau de produtividade desses ambientes. Para isto, foram utilizados dados de monitoramento da qualidade da água da lagoa, do período de setembro de 1993 a dezembro de 2002 , para os seguintes parâmetros: temperatura da água, cores real e aparente, pH, oxigênio dissolvido, sólidos suspensos, sólidos dissolvidos, turbidez, demanda bioquímica de oxigênio, demanda química de oxigênio, série nitrogenada, fósforo total, ortofosfatos, ferro solúvel, ferro total, coliformes fecais, coliformes totais, clorofila-a, cloretos, condutividade e salinidade. Foram também levantados dados de monitoramento dos potenciais efluentes industriais e de variáveis meteorológicas. Realizaram-se testes estatísticos com os dados, com um nível de significância de 5\%. Resultados foram comparados com limites estabelecidos pela legislação vigente. A lagoa Mãe-Bá apresentou características comuns a lagoas costeiras em geral. A sazonalidade influenciou fortemente a temperatura da água da lagoa, que não apresentou estratificação térmica e mostrou perfil de oxigênio dissolvido do tipo ortogrado, principalmente devido às baixas profundidades e à ação dos ventos. A lagoa apresenta águas ligeiramente salobras, e valores de condutividade menores que os de lagoas costeiras fortemente influenciadas pelo mar. Os resultados das classificações tróficas indicadas pelo Índice de Estado Trófico Modificado e pela metodologia de distribuição de probabilidade de estado trófico baseada em concentrações de fósforo total determinaram condições eutróficas na lagoa em pontos situados próximos a descargas de efluentes domésticos. Aumento sistemático do pH ao longo dos anos, supersaturação de oxigênio dissolvido, valores elevados de fósforo total, diferenças entre os parâmetros cor aparente e real, DQO bruta e filtrada e crescimento da densidade do fitoplâncton, constituída tipicamente por cianobactérias, indicam a existência de processo de eutrofização na lagoa Mãe-Bá.

Palavras-chave: Descritores: lagoas costeiras; influências naturais e antrópicas; qualidade de águas; eutrofização.

\section{INTRODUÇÃO}

Lagoas costeiras são ecossistemas ecologicamente e economicamente importantes que apresentam características e processos comuns a sistemas marinhos em geral, mas mostram também aspectos particulares, dependentes de influências naturais e antrópicas em suas bacias hidrográficas (Lasserre, 1979). A grande diversidade das características naturais de lagoas costeiras, bem como das diferentes influências antrópicas a que estão submetidas mos- tram que características ecológicas comuns a esses ecossistemas são raras (Nixon, 1982). É somente gerando informações em lagoas individuais e difundindo-as largamente na comunidade científica que uma descrição da biologia de lagoas em geral pode ser montada (Barnes, 1980). O conhecimento do ecossistema baseado em investigações sistemáticas de variáveis ambientais permite descrevê-lo, no que diz respeito à sua estrutura e funcionamento, podendo evidenciar as complexas interações entre os vários componentes do ecossistema (Esteves, 1988). 
Um importante problema que afeta ambientes lênticos é o aumento excessivo de suas produtividades, resultando no crescimento exagerado de organismos aquáticos autotróficos, principalmente algas planctônicas (fitoplâncton) e vegetação aquática (macrófitas). Esse processo, denominado eutrofização, ocorre naturalmente na maioria das lagoas, pois elas funcionam como um depósito de nutrientes provenientes do oceano e de sua bacia hidrográfica. No entanto, este processo é favorecido pelo crescimento populacional, industrial e pela intensificação da agricultura, que elevam a quantidade de nutrientes que alcançam os corpos d'água (Vollenweider, 1981). A produtividade primária depende da disponibilidade de vários nutrientes, principalmente de oxigênio, carbono, nitrogênio e fósforo. A insuficiência de qualquer um dos nutrientes pode provocar limitação do crescimento. Em alguns casos, a luz e a temperatura podem atuar como fatores limitantes ao crescimento de fitoplâncton e macrófitas. A classificação do estado trófico de ambientes lênticos envolve o estabelecimento de níveis ou limites baseados no grau ou intensidade do processo da eutrofização e das suas conseqüências.

Foram desenvolvidas várias metodologias para determinação do nível trófico de lagos e reservatórios. A maioria delas aplica-se a lagos de clima temperado, que mostram mais freqüentemente ser o fósforo o principal fator limitante da produtividade. Dentre as metodologias para classificação trófica adaptadas à realidade dos lagos tropicais, pode-se citar aquelas desenvolvidas por Toledo Jr. et. al. (1984) e Salas e Martino (1991). Visando definir a aplicabilidade do modelo de Índice de Estado Trófico (IET) de Carlson aos lagos e reservatórios brasileiros, Toledo Jr. et al. (1984) propuseram uma modificação na formulação matemática do cálculo do IET, com base nos resultados obtidos em uma pesquisa realizada no reservatório de Barra Bonita SP, no período de 1978 a 1980. No Programa Regional do Centro Panamericano de Ingeniería Sanitaria y Ciencias del Ambiente (CEPIS), Salas e Martino (1991) utilizaram 39 dados, correspondentes a 27 lagos e reservatórios, incluindo-se algumas lagoas costeiras, localizados em regiões de clima tropical. $\mathrm{O}$ estudo permitiu a observação de concentrações de fósforo total e suas relações com os níveis tróficos dos respectivos corpos d'água, definidos segundo critérios similares aos observados por Vollenweider (1983). Esse estudo resultou em uma distribuição de probabilidade condicional para as categorias de estado trófico, que permite determinar a probabilidade percentual de estado trófico de um lago ou reservatório com base na concentração de fósforo total.

Objetiva-se analisar as influências de aspectos naturais e atividades antrópicas sobre parâmetros de qualidade de água da lagoa Mãe-Bá e caracterizar seu nível trófico.

\section{MATERIAIS E MÉTODOS}

A lagoa Mãe-Bá localiza-se na divisa dos municípios de Guarapari e Anchieta, no litoral sul do estado do Espírito Santo, entre o balneário de Meaípe e o Porto Marítimo de Ubu. Em época anterior a 1970, ocorreu o fechamento do canal de ligação entre a lagoa Mãe-Bá e o mar, por meio de aterro, para a construção da pista da Rodovia do Sol, impedindo assim o fluxo de entrada e saída das águas do mar e da lagoa. É a segunda maior lagoa do Estado, possui forma alongada, com área média de $4,9 \mathrm{~km}^{2} \mathrm{e}$ profundidade média de $1,9 \mathrm{~m}$. A lagoa possui pequenos córregos afluentes, que apresentam limitada disponibilidade hídrica devido ao elevado estágio de degradação do solo e à construção de barragens. A figura 1 apresenta mapa de localização da lagoa Mãe-Bá.

As águas da lagoa Mãe-Bá apresentam múltiplos usos. Destaca-se por ser manancial de abastecimento doméstico das populações vizinhas, após tratamento e distribuição pela companhia de abastecimento, e pela exploração de poços rasos pelas comunidades ribeirinhas. Suas águas são também utilizadas como receptoras e diluidoras dos efluentes domésticos sem tratamento, proveniente de uma população de cerca de 3.500 pessoas situadas em sua bacia hidrográfica. A empresa de pelotização Samarco Mineração S/A utiliza os recursos hídricos da lagoa como receptora de seus efluentes industriais. A empresa possui uma barragem industrial, denominada Barragem Norte, que recebe os efluentes industriais após passar por três etapas de tratamento. A conexão da barragem com a lagoa ocorre por meio de um barramento, que é aberto, em média, quatro vezes por ano. A vazão média anual do efluente da barragem é estimada em $150 \mathrm{~m}^{3} / \mathrm{h}$. Outros usos das águas da lagoa Mãe-Bá incluem a pesca e o lazer.

Dados de monitoramento da qualidade da água da lagoa Mãe-Bá, disponibilizados pela empresa Samarco Mineração S/A, no período de setembro de 1993 a dezembro de 2002, foram utilizados para avaliação da evolução histórica dos seguintes parâmetros: temperatura da água (T-Água), cor aparente (Cor A.), pH, oxigênio dissolvido (O. D.), sólidos 


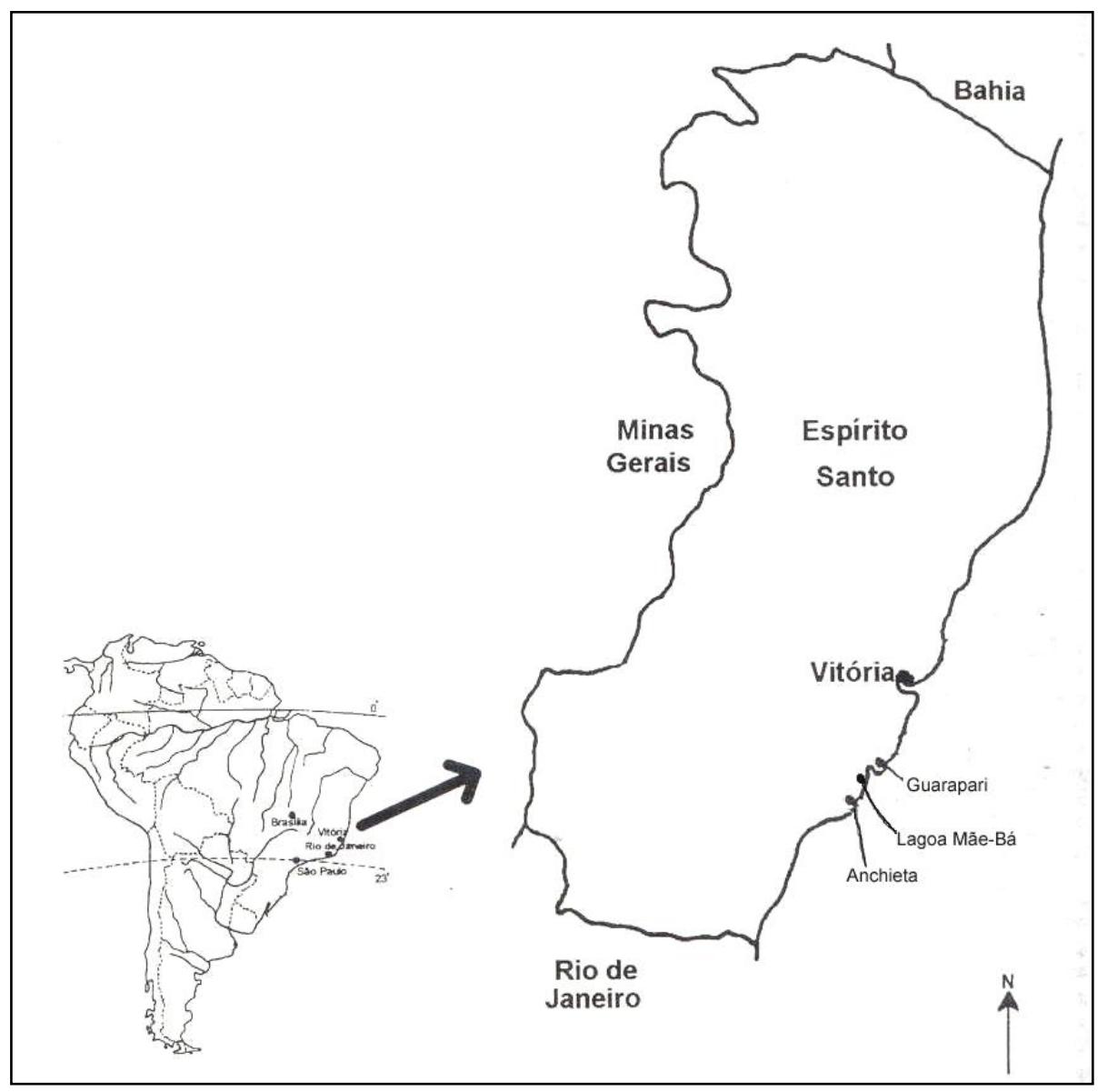

Figura 1 - Localização da lagoa Mãe-Bá

suspensos (S-Susp.), sólidos dissolvidos (S-Diss.), turbidez (Turb.), demanda bioquímica de oxigênio (DBO), demanda química de oxigênio não filtrada (DQO b.), nitrogênio total (N-Total), fósforo total (P-Total), ferro solúvel (Fe-Sol), ferro total (FeTotal), coliformes fecais (Col. F.) e coliformes totais (Col. T.). As amostras foram coletadas na superfície da coluna d’água (20 $\mathrm{cm}$ de profundidade) e analisadas segundo as revisões vigentes do "Standard Methods for the Examination of Water and Wastewater". Os pontos monitorados foram denominados LM-B (localizado próximo do vertedouro dos efluentes industriais) e LM-E (ponto mais profundo, próximo ao lançamento de esgotos domésticos). Foram também utilizados dados históricos de monitoramento do potencial efluente industrial proveniente da usina de pelotização, em local situado próximo à comporta da Barragem Norte, denominado ponto BN. Mapa de localização dos pontos de monitoramento é apresentado na figura 2.
Com o objetivo de complementar os dados históricos disponíveis para uma análise mais abrangente das condições ambientais da lagoa Mãe-Bá, foram realizadas quatro campanhas de monitoramento ao longo do ano de 2002 para coleta de amostras na superfície em sete pontos na lagoa MãeBá (coletadas a $20 \mathrm{~cm}$ de profundidade), dos quais para três deles também foram feitas amostragens de fundo (coletadas a $50 \mathrm{~cm}$ do fundo da lagoa, com o auxílio da garrafa de Van Dorn). Os pontos estão representados na figura 2. As campanhas foram distribuídas de modo que a variação sazonal da qualidade da água da lagoa pudesse ser avaliada (25/03, 19/06, 02/10 e 18/12). As amostras coletadas foram analisadas para os seguintes parâmetros: cores real (Cor R.) e aparente (Cor A.), sólidos suspensos (SSusp.), sólidos dissolvidos (S-Diss.), turbidez (Turb.), demanda bioquímica de oxigênio (DBO), demanda química de oxigênio bruta (DQO b.) e filtrada (DQO f.), nitrogênio amoniacal $\left(\mathrm{N}-\mathrm{NH}_{3}\right)$, 




Figura 2 - Localização dos pontos de monitoramento.

nitritos $\left(\mathrm{N}-\mathrm{NO}_{2}\right)$, nitratos $\left(\mathrm{N}-\mathrm{NO}_{3}\right)$, nitrogênio orgânico (N-Org.), nitrogênio total (N-Total), fósforo total (P-Total), ortofosfatos $\left(\mathrm{P}-\mathrm{PO}_{4}\right)$, clorofila-a $(\mathrm{Cl}-$ a), coliformes fecais (Col. F.), coliformes totais (Col. T.) e cloretos $\left(\mathrm{Cl}^{-}\right)$. Foram realizadas, com o auxílio do Disco Sechhi, medições da transparência da coluna d'água (Transp.). Foram obtidos junto à companhia de abastecimento dados de monitoramento do fitoplâncton nos pontos de captação de água (pontos LM-C e LM-F, Figura 2), coletados em freqüências variadas no período considerado. As análises foram realizadas segundo o "Standard Methods for the Examination of Water and Wastewater" (APHA, 1998).
Em todos os pontos, além das coletas foram feitas sondagens com o equipamento Hydrolab, com determinação instantânea dos parâmetros oxigênio dissolvido (O.D.), pH, condutividade elétrica (Cond.), salinidade (Salin.) e temperatura (TÁgua).

Os resultados da lagoa foram comparados com os limites estabelecidos na Resolução CONAMA N. ${ }^{\circ}$ 20, de 18 de junho de 1986, para águas enquadradas como classes 2 e 7. Dados da Barragem Norte foram comparados com os limites definidos para efluentes na referida Resolução.

Dados meteorológicos referentes a precipitação pluviométrica (PrecPluv), temperatura do ar (T-Ar), radiação solar (Rad-Solar) e velocidade dos 
ventos (Vel-Ventos N-S; Vel-Ventos E-W) foram obtidos a partir da estação metereológica integrada localizada na área interna da Samarco, situada a 2,0 $\mathrm{Km}$ ao sul da lagoa.

Inicialmente foi realizada uma análise descritiva dos resultados. A evolução dos dados foi visualizada através de gráficos de séries temporais, estabelecidas através das médias dos valores diários em cada trimestre. Foram também construídos gráficos das médias trimestrais de acordo com o local de coleta.

A ocorrência de diferenças nas concentrações das variáveis entre os locais de coleta na lagoa e entre as campanhas foi testada através da técnica de análise de variância (ANOVA) e do teste nãoparamétrico de Kruskal-Wallis.

Aplicou-se também a técnica de análise discriminante (com função discriminante linear) aos locais de coleta na lagoa considerando as médias trimestrais das variáveis.

Resultados de monitoramento que se mostraram abaixo do limite de detecção da metodologia de análise foram considerados, para fins de análise estatística, com os valores iguais aos limites de detecção. As variáveis que apresentaram essa característica foram Fe-Sol, Fe-Total, P-Total, Col. F. e Col $\mathrm{T}$.

\section{RESULTADOS E DISCUSSÃO}

As figuras 3 a 17 apresentam os gráficos de séries temporais e gráficos das médias trimestrais das variáveis de qualidade de água, de acordo com o local de coleta.

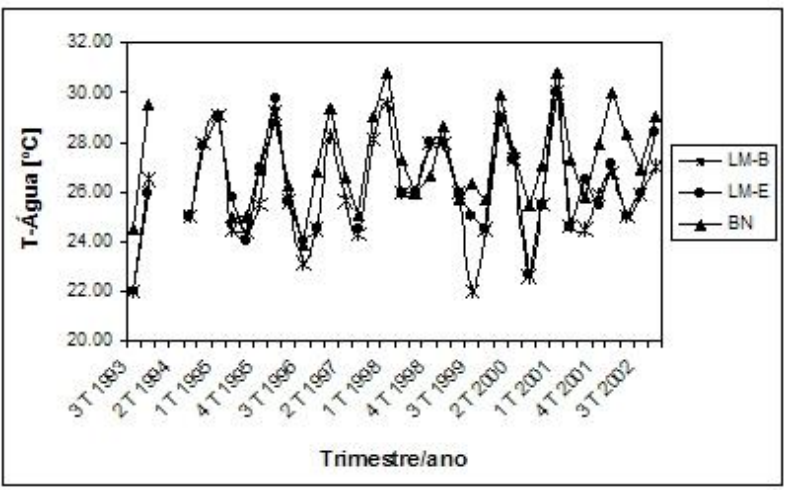

Figura 3 - Gráfico das séries históricas das médias trimestrais e gráfico das médias dos trimestres das medições de T-Água - pontos LM-B, LM-E e BN.

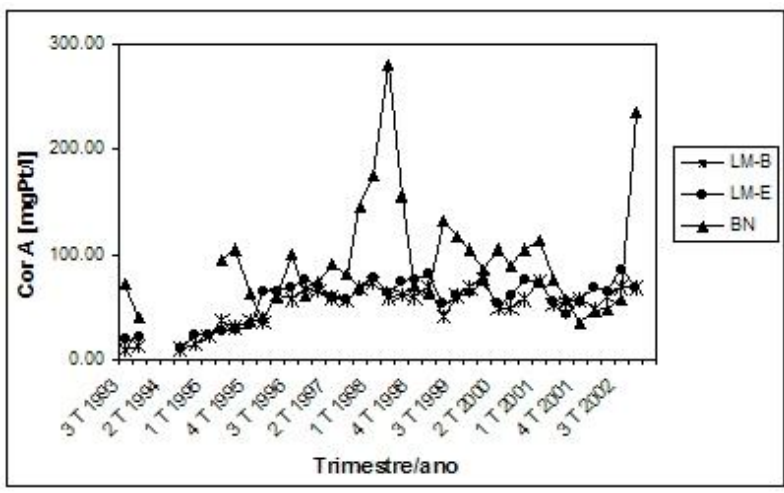

Figura 4 - Gráfico das séries históricas das médias trimestrais e gráfico das médias dos trimestres das medições de Cor A. - pontos LM-B, LM-E e BN.

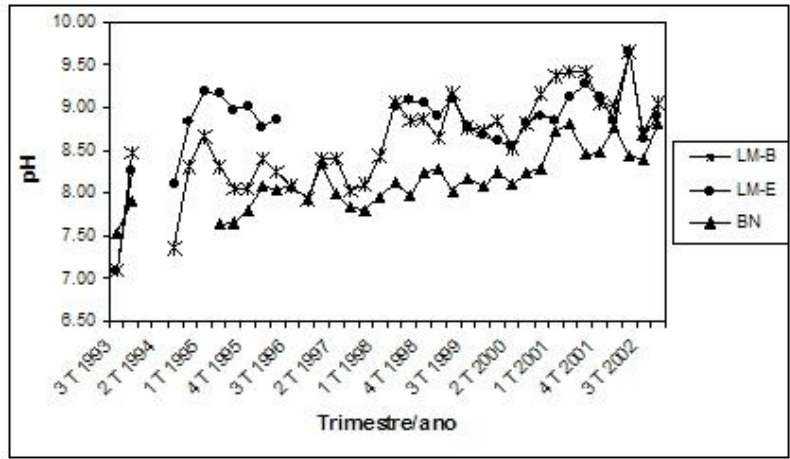

Figura 5 - Gráfico das séries históricas das médias trimestrais e gráfico das médias dos trimestres das medições de pH - pontos LM-B, LM-E e BN.

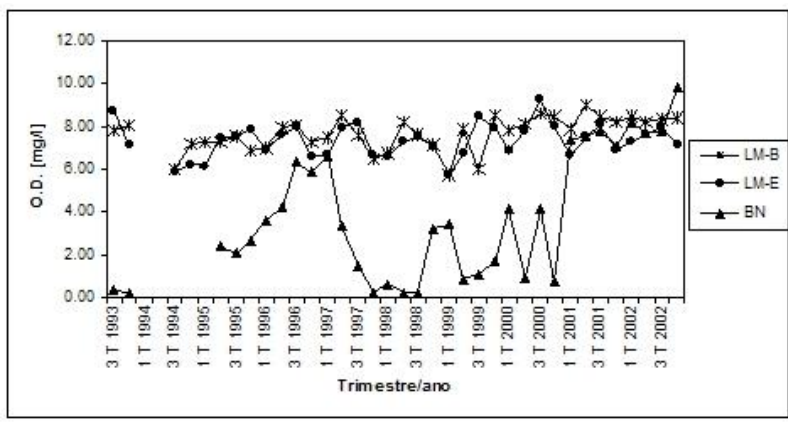

Figura 6 - Gráfico das séries históricas das médias trimestrais e gráfico das médias dos trimestres das medições de O.D. - pontos LM-B, LM-E e BN. 


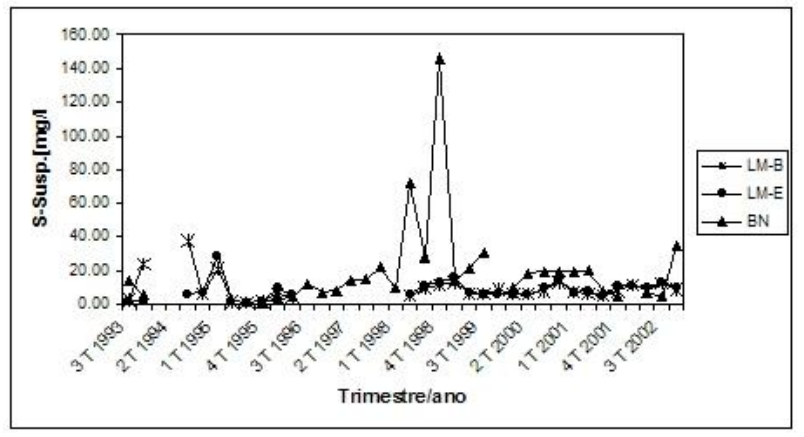

Figura 7 - Gráfico das séries históricas das médias trimestrais e gráfico das médias dos trimestres das medições de S-Susp. - pontos LM-B, LM-E e BN.

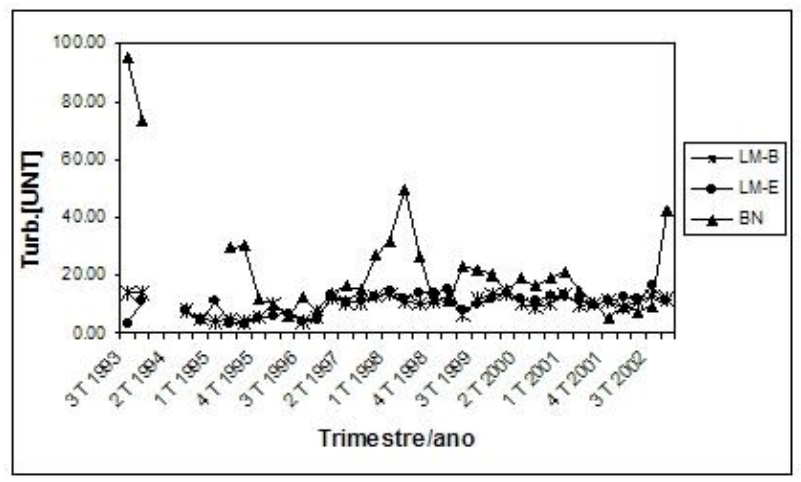

Figura 8 - Gráfico das séries históricas das médias trimestrais e gráfico das médias dos trimestres das medições de Turb. - pontos LM-B, LM-E e BN.

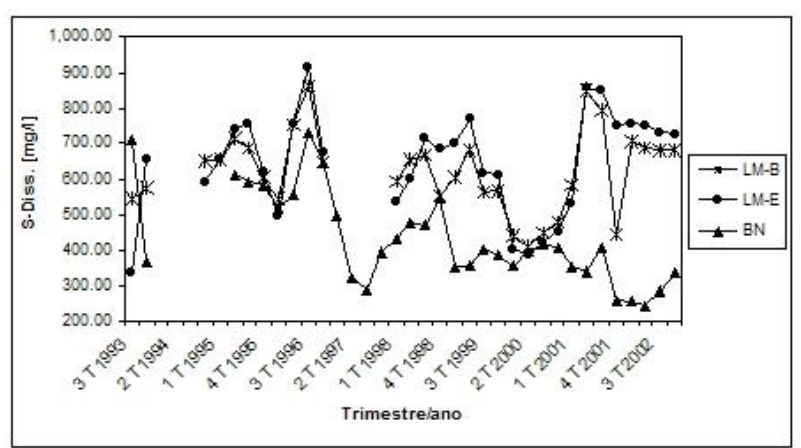

Figura 9 - Gráfico das séries históricas das médias trimestrais e gráfico das médias dos trimestres das medições de S-Diss. - pontos LM-B, LM-E e BN.



Figura 10 - Gráfico das séries históricas das médias trimestrais e gráfico das médias dos trimestres das medições de DBO - pontos LM-B, LM-E e BN.



Figura 11 - Gráfico das séries históricas das médias trimestrais e gráfico das médias dos trimestres das medições de DQO b. - pontos LM-B, LM-E e BN.



Figura 12 - Gráfico das séries históricas das médias trimestrais e gráfico das médias dos trimestres das medições de N-Total - pontos LM-B, LM-E e BN. 


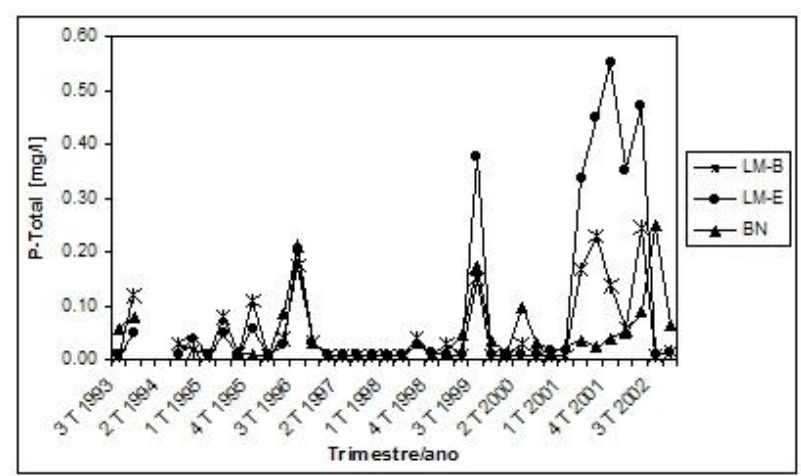

Figura 13 - Gráfico das séries históricas das médias trimestrais e gráfico das médias dos trimestres das medições de P-Total - pontos LM-B, LM-E e BN.

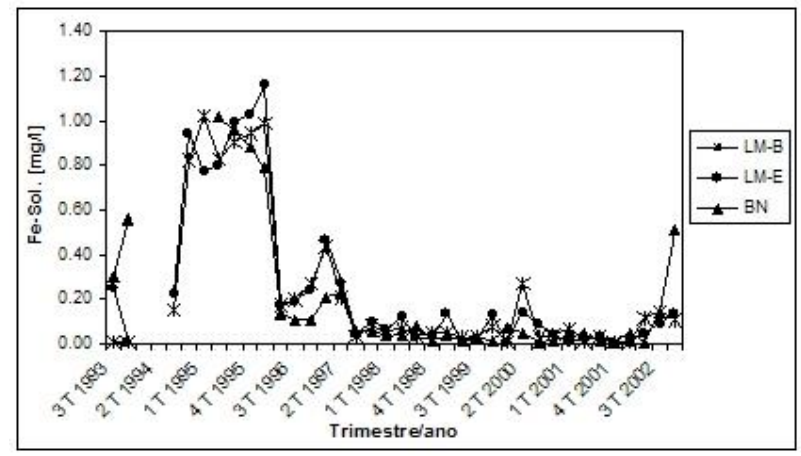

Figura 14 - Gráfico das séries históricas das médias trimestrais e gráfico das médias dos trimestres das medições de Fe-Sol. - pontos LM-B, LM-E e BN.



Figura 15 - Gráfico das séries históricas das médias trimestrais e gráfico das médias dos trimestres das medições de Fe-Total - pontos LM-B, LM-E e BN.

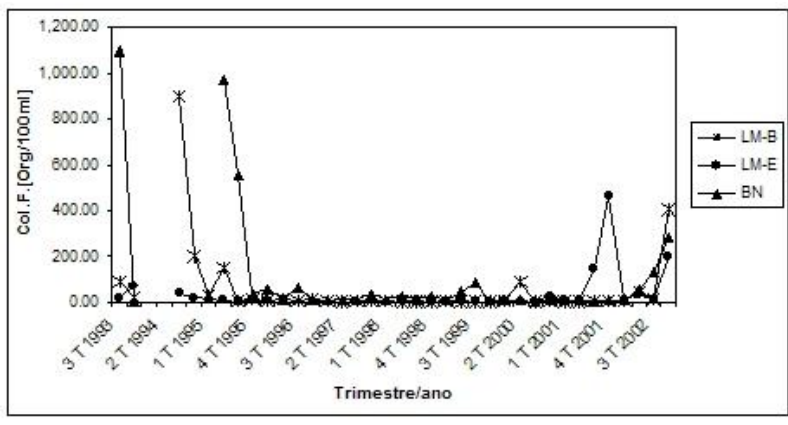

Figura 16 - Gráfico das séries históricas das médias trimestrais e gráfico das médias dos trimestres das medições de Col. F. - pontos LM-B, LM-E e BN.

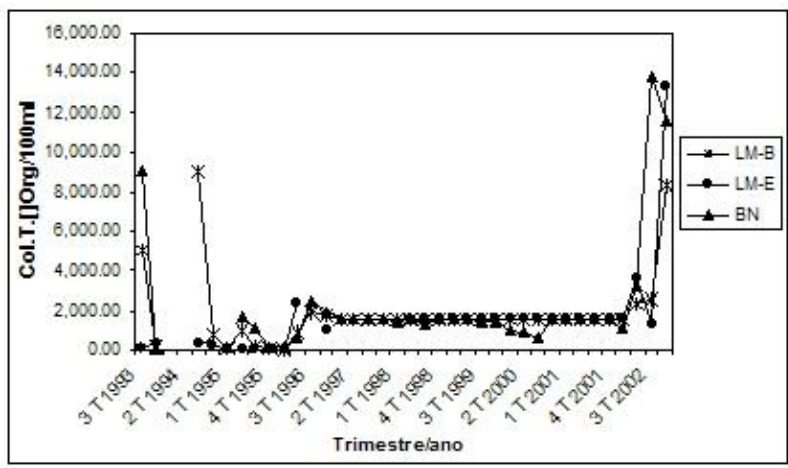

Figura 17 - Gráfico das séries históricas das médias trimestrais e gráfico das médias dos trimestres das medições de Col. T. - pontos LM-B, LM-E e BN.

A análise qualitativa das médias históricas trimestrais da lagoa Mãe-Bá indicou alguns parâmetros em desacordo com os limites estabelecidos pela Resolução CONAMA N. ${ }^{\circ} 20$ de 18 de junho de 1986, para águas classe 2 (cor aparente, $\mathrm{pH}$, sólidos dissolvidos, demanda bioquímica de oxigênio, fósforo total e ferro solúvel) e classe 7 ( $\mathrm{pH}$ e demanda bioquímica de oxigênio). Os parâmetros que apresentam limites para efluentes na referida Resolução (TÁgua, pH e Fe-Sol.) mostraram valores conformes na Barragem Norte.

A tabela 1 mostra os níveis descritivos (p) do teste $\mathrm{F}$ e do teste não-paramétrico de Kruskal-Wallis aplicados na avaliação do efeito do local e do trimestre de coleta sobre as variáveis, nos pontos de coleta na lagoa Mãe-Bá (LM-B e LM-E). 
Os resultados das médias históricas trimestrais das variáveis temperatura da água, $\mathrm{pH}$, oxigênio dissolvido, demanda química de oxigênio, nitrogênio total e coliformes fecais mostraram diferenças significativas $(\mathrm{p}<0,05)$ em relação ao local de coleta na lagoa Mãe-Bá, indicando que as influências antrópicas e naturais atuam de modo diferenciado em relação aos pontos de coleta na lagoa.

Os resultados das médias históricas trimestrais das variáveis temperatura da água, cor aparente, $\mathrm{pH}$, oxigênio dissolvido, turbidez, sólidos dissolvidos, demanda química de oxigênio, ferro solúvel e ferro total mostraram diferenças significativas $(p<0,05)$ em relação ao trimestre de coleta na lagoa Mãe-Bá, indicando influências de fatores naturais nas variáveis de qualidade de água.

Tabela 1 - Níveis descritivos (p) dos testes dos efeitos do local de coleta e do trimestre sobre as variáveis - pontos LM-B e LM-E.

\begin{tabular}{|l|c|c|c|}
\hline \multirow{2}{*}{ Variáveis } & \multicolumn{3}{|c|}{$\mathrm{p}$} \\
\cline { 2 - 4 } & Local & Trimestre & Local x trim. \\
\hline T-Água & $<0,0005$ & $<0,0005$ & - \\
\hline Cor A. & 0,294 & 0,015 & 0,418 \\
\hline $\mathrm{pH}$ & $<0,0005$ & $<0,0005$ & - \\
\hline O. D. & 0,054 & $<0,0005$ & - \\
\hline S-Susp. & 0,982 & 0,109 & 0,772 \\
\hline Turb. & 0,342 & $<0,0005$ & 0,868 \\
\hline S-Diss. & 0,399 & $<0,0005$ & 0,532 \\
\hline DBO & 0,588 & 0,089 & 0,453 \\
\hline DQO b. & $<0,0005$ & 0,022 & 0,495 \\
\hline N-Total & 0,034 & 0,176 & 0,204 \\
\hline P-Total & 0,932 & 0,066 & - \\
\hline Fe-Sol. & 0,456 & 0,036 & - \\
\hline Fe-Total & 0,303 & 0,016 & 0,990 \\
\hline Col. F. & 0,024 & 0,104 & - \\
\hline Col. T. & 0,946 & 0,185 & - \\
\hline
\end{tabular}

A sazonalidade influenciou a temperatura da água da lagoa Mãe-Bá, a qual acompanhou as variações de temperatura do ar. A incidência de chuvas resultou no aumento das concentrações de cor aparente, demanda bioquímica de oxigênio, coliformes fecais e coliformes totais nas águas da lagoa Mãe-Bá. No entanto, o efeito de diluição das chuvas atuou no sentido de diminuir as concentrações de sólidos dissolvidos, de fósforo total, de ferro solúvel e de ferro total.

A influência marinha foi observada através das concentrações de sólidos dissolvidos, mais eleva- das na lagoa Mãe-Bá. As alternâncias entre baixas e elevadas concentrações de fósforo total na lagoa sugerem a precipitação de íons fosfato pelos sedimentos, através da adsorção por óxidos e hidróxidos de ferro, e solubilização decorrente das baixas profundidades e ação dos ventos.

A influência do processo de pelotização foi indicada pelas concentrações de cor aparente, sólidos suspensos e turbidez na Barragem Norte, que constitui-se em um ambiente propício à degradação da matéria orgânica. $\mathrm{O}$ aumento sistemático do $\mathrm{pH}$, associado à disponibilidade de nitrogênio, indica elevada produtividade primária nesse ambiente em condições favoráveis de luz e fósforo. O incremento nos sistemas de controle de efluentes industriais, com a implantação da terceira etapa de tratamento (em novembro de 1995) e a disposição final dos esgotos domésticos da usina de pelotização através de valas de infiltração (a partir de 1996), refletiram na diminuição das concentrações de ferro solúvel, ferro total e coliformes fecais nas águas da lagoa Mãe-Bá.

As razões médias de nitrogênio e fósforo para os dados históricos trimestrais na lagoa Mãe-Bá indicaram, na maioria dos trimestres, que o crescimento do fitoplâncton foi limitado pelo fósforo.

Segundo a metodologia de distribuição de probabilidade de estado trófico baseado em concentrações de fósforo total (Salas; Martino, 1991), a lagoa Mãe-Bá apresentou características mesotróficas no ponto LM-B e eutróficas no ponto LM-E, com valores médios históricos de fósforo de $50 \mathrm{mg} / \mathrm{m}^{3} \mathrm{e}$ $90 \mathrm{mg} / \mathrm{m}^{3}$, respectivamente.

É importante ressaltar que o modelo de fósforo total aplicado não leva em consideração a resposta das macrófitas à entrada de nutrientes, produtores primários importantes na lagoa Mãe-Bá, que cobrem atualmente cerca de $30 \%$ da área de seu espelho d'água.

As tabelas 2 a 4 mostram os resultados das análises laboratoriais das amostras coletadas nos sete pontos da lagoa Mãe-Bá, nas quatro campanhas de monitoramento em 2002.

A análise qualitativa dos resultados de monitoramento na lagoa Mãe-Bá nas campanhas em 2002 indicou alguns parâmetros em desacordo com os limites estabelecidos pela Resolução CONAMA N. ${ }^{\circ}$ 20 de 18 de junho de 1986, para águas classe 2 (cor aparente, $\mathrm{pH}$, sólidos dissolvidos, fósforo total e cloretos) e classe $7(\mathrm{pH})$.

As diferenças nas concentrações de Cor A. e Cor R. e DQO b. e DQO f. indicaram presença de matéria orgânica em suspensão. Foi observado pré 
Tabela 2 - Amostragem na lagoa - $1^{\mathrm{a}}$ a $4^{\mathrm{a}}$ campanhas - pontos LM-A a LM-G.

\begin{tabular}{|c|c|c|c|c|c|c|c|c|c|c|c|c|c|c|c|c|c|c|c|c|c|}
\hline \multirow[t]{2}{*}{\begin{tabular}{|l|} 
Local \\
\end{tabular}} & \multicolumn{3}{|c|}{ S-Susp. } & \multicolumn{3}{|c|}{ S-Diss } & \multicolumn{3}{|c|}{ DQO f. } & \multicolumn{3}{|c|}{ DQO b. } & \multicolumn{3}{|c|}{ DBO } & \multicolumn{3}{|c|}{$\mathrm{Cl}-\mathrm{a}$} & \multicolumn{3}{|c|}{ Transp. } \\
\hline & Min. & Med & Max. & Min. & Med & Max. & Min. & Med & Max. & Min. & Med & Max. & Min. & Med & Max. & Min. & Med & Max. & Min. & Med & Max. \\
\hline \begin{tabular}{|l} 
LM-A \\
\end{tabular} & 4 & 9 & 12 & 631 & 665 & 733 & 28,4 & 53,7 & 113,3 & 51,2 & 79,4 & \begin{tabular}{|l|}
155,0 \\
\end{tabular} & 1,60 & 2,11 & 2,85 & $<0,01$ & 1,90 & 3,98 & 0,07 & 0,80 & 1,00 \\
\hline LM-B & 6 & 10 & 13 & 636 & 677 & 744 & 26,0 & 46,8 & 85,0 & 48,4 & 60,3 & 85,0 & 1,50 & 2,25 & 3,05 & $<0,01$ & 1,46 & 2,51 & 0,70 & 0,87 & 1,10 \\
\hline \begin{tabular}{|l|}
$L M-B(f)$ \\
\end{tabular} & 7 & 8 & 10 & 641 & 652 & 672 & 27,6 & 32,3 & 38,4 & 57,6 & 61,0 & 67,2 & 1,70 & 2,35 & 2,80 & $<0,01$ & 1,14 & 2,14 & - & - & - \\
\hline \begin{tabular}{|l|} 
LM-C \\
\end{tabular} & 9 & 11 & 13 & 681 & 709 & 766 & 30,4 & 55,1 & 115,0 & 51,2 & 78,7 & 151,6 & 1,65 & 2,36 & 3,05 & 0,89 & 1,62 & 2,18 & 0,70 & 0,77 & 0,80 \\
\hline \begin{tabular}{|l|} 
LM-D \\
\end{tabular} & 8 & 10 & 13 & 668 & 709 & 804 & 29,6 & 42,7 & 70,0 & 57,2 & 72,5 & \begin{tabular}{|l|}
115,0 \\
\end{tabular} & 2,00 & 2,23 & 2,85 & $<0,01$ & 1,31 & 2,54 & 0,80 & 0,90 & 1,10 \\
\hline LM-D(f) & 8 & 10 & 11 & 670 & 680 & 685 & 33,6 & 36,4 & 39,6 & 58,4 & 60,8 & \begin{tabular}{|l|}
62,8 \\
\end{tabular} & 2,05 & 2,45 & 3,20 & $<0,01$ & 2,65 & 6,59 & - & - & - \\
\hline LM-E & 6 & 9 & 11 & 691 & 725 & 789 & 30,8 & 47,1 & 71,6 & 56,4 & 110,9 & 265,0 & 1,85 & 2,14 & 2,70 & $<0,01$ & 1,45 & 2,41 & 0,70 & 0,77 & 0,90 \\
\hline LM-E(f) & 10 & 12 & 14 & 695 & 702 & 707 & 32,8 & 39,4 & 46,8 & 58,4 & 60,5 & 63,6 & 2,30 & 2,63 & 3,10 & 1,69 & 2,07 & 2,45 & - & - & - \\
\hline \begin{tabular}{|l|} 
LM-F \\
\end{tabular} & 4 & 7 & 13 & 685 & 729 & 808 & 34,4 & 57,1 & 120,0 & 57,6 & 83,4 & 151,6 & 2,00 & 2,31 & 2,75 & 0,98 & 3,92 & 7,65 & 0,70 & 0,83 & 1,00 \\
\hline \begin{tabular}{|l} 
LM-G \\
\end{tabular} & 5 & 10 & 13 & 643 & 701 & 815 & 32,0 & 47,8 & 80,0 & 53,6 & 63,7 & 86,6 & 2,25 & 2,46 & 2,90 & 0,69 & 1,51 & 2,71 & 0,70 & 0,83 & 1,00 \\
\hline
\end{tabular}

Tabela 3 - Amostragem na lagoa - $1^{\mathrm{a}}$ a $4^{\mathrm{a}}$ campanhas - pontos LM-A a LM-G.

\begin{tabular}{|c|c|c|c|c|c|c|c|c|c|c|c|c|c|c|c|c|c|c|c|c|c|}
\hline \multirow[t]{2}{*}{ _ocal } & \multicolumn{3}{|c|}{$\mathrm{N}-\mathrm{NH}_{3}$} & \multicolumn{3}{|c|}{$\mathrm{N}-\mathrm{NO}_{2}$} & \multicolumn{3}{|c|}{$\mathrm{N}-\mathrm{NO}_{3}$} & \multicolumn{3}{|c|}{$\mathrm{N}$-Org. } & \multicolumn{3}{|c|}{ N-Total } & \multicolumn{3}{|c|}{$\bar{P}-\mathrm{PO}_{4}$} & \multicolumn{3}{|c|}{ P-Total } \\
\hline & n. & Med & ax. & & Med & Max. & in. & Med & $\mathrm{M}$ & in. & Med & Max & iin & \begin{tabular}{|l|} 
Med \\
\end{tabular} & Max & /in & Med & Max. & Min. & Med & $\overline{\mathrm{Ma}}$ \\
\hline A-A & 0,07 & 0,19 & 0,30 & 009 & \begin{tabular}{|l|}
0,014 \\
\end{tabular} & 0,016 & 0,1 & 0,5 & 0,8 & 05 & 0,1 & 0,25 & \begin{tabular}{|l|}
0,12 \\
\end{tabular} & 0,46 & \begin{tabular}{|l|}
0,75 \\
\end{tabular} & 0,01 & 0,06 & 0,12 & 0,01 & 28 & 0,57 \\
\hline & & & & & & & 0 & & & & & & & & & & & 0,14 & & & 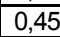 \\
\hline B & & & & & & & & & & & & & & & & & & & & &, 52 \\
\hline $\mathrm{M}-\mathrm{C}$ & & & & & & & & & & & & & & & & & & 19 & 0, & &, 58 \\
\hline & & & 0,32 & 6 & & & 0, & & & & & & & & 0, & 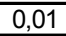 & 06 & 12 & 0,01 & 17 &, 46 \\
\hline & & & & & & & & & & & & & & & & & & & & &, 54 \\
\hline & & $0, \angle U$ & 0,26 & & & & & & & & & 0 & & 0,5 & 0,88 & 0,0 & 08 &, 21 & 1 & 29 & 1,65 \\
\hline N-E(f) & 0,18 & \begin{tabular}{|l|}
0,20 \\
\end{tabular} & 0,22 & 013 & 0,014 & $\overline{0,016}$ & 0,8 & 1,0 & 1, & 0,15 & 0, & 0,18 & 0,58 & \begin{tabular}{|l|}
0,60 \\
\end{tabular} & 0,63 & 0,01 & 0,04 & 0,11 & 0,01 &, 23 & 0,65 \\
\hline A-F & 0,05 & 0,16 & 0,25 & 0,013 & 015 & 0,019 & $\overline{0,4}$ & 0, & 1, & 0,04 & 0, & 0,21 & 0,19 & 0,51 & 0,86 & 0,01 & 0,09 & 0,22 & 0,02 & 22 & 0,50 \\
\hline$A-G$ & 0,23 & 0,31 & 0,36 & 009 & 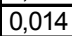 & & 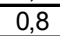 & 1,3 & 2, & 0,19 & 0,2 & 0,2 & 0,62 & 0,86 & 1,12 & 0,01 & 0,06 & 0,14 & 0,01 & 0,18 & 0,4 \\
\hline
\end{tabular}

Tabela 4 - Amostragem na lagoa - $1^{\mathrm{a}}$ a $4^{\mathrm{a}}$ campanhas - pontos LM-A a LM-G.

\begin{tabular}{|c|c|c|c|c|c|c|c|c|c|c|c|c|c|c|c|c|c|c|}
\hline \multirow[t]{2}{*}{ Local } & \multicolumn{3}{|c|}{ Cor R. } & \multicolumn{3}{|c|}{ Cor A } & \multicolumn{3}{|c|}{ Turb. } & \multicolumn{3}{|c|}{$\mathrm{Cl}^{-}$} & \multicolumn{3}{|c|}{ Col. F. } & \multicolumn{3}{|c|}{ Col.T. } \\
\hline & Min. & Med & Max. & Min. & Med & Max. & Min. & Med & Max. & Min. & Med & Max. & Min. & Med & Max. & Min. & Med & Max. \\
\hline LM-A & $<1$ & 4 & 14 & 33 & 44 & 61 & 6 & 9 & 12 & 231 & 215 & 271 & $<2$ & 61 & 129 & 1100 & & 13100 \\
\hline \begin{tabular}{|l|} 
LM-B \\
\end{tabular} & 1 & 5 & 16 & 32 & & t & 7 & & 12 & 231 & 248 & 272 & 4 & 5 & 87 & 1600 & 5 & 10000 \\
\hline LM-B $(\mathrm{f}$ & $<1$ & 5 & 12 & 33 & & 66 & 6 & & 13 & 229 & 38 & 249 & 35 & 130 & 226 & 1700 & 00 & 13200 \\
\hline \begin{tabular}{|l|}
$L M-C$ \\
\end{tabular} & $<1$ & 4 & 11 & 34 & & 74 & 8 & 1 & 14 & 248 & $\sqrt{26}$ & 287 & 9 & 1463 & 4825 & 1600 & 775 & 16900 \\
\hline LM-D & $<1$ & & & 38 & & 71 & 8 & & 1 & 248 & & 302 & 4 & $\pi$ & 222 & 200 & & 10600 \\
\hline LM-D(f & $<1$ & & 15 & 41 & & $\overline{7 \varepsilon}$ & $\mathrm{c}$ & & 1 & 249 & 257 & 269 & 9 & 3 & 246 & 3800 & 0 & 11000 \\
\hline \begin{tabular}{|l|} 
LM-E \\
\end{tabular} & $<1$ & $\sqrt{3}$ & 16 & 40 & 54 & 65 & 0 & 10 & 13 & 261 & 278 & 307 & $<2$ & 79 & 208 & 1600 & \begin{tabular}{|l|}
6975 \\
\end{tabular} & 14700 \\
\hline LM-E(f) & $<1$ & 5 & 14 & 45 & 58 & 77 & 10 & 12 & 15 & 260 & 268 & 275 & 141 & 177 & 212 & 8400 & 11867 & 16800 \\
\hline \begin{tabular}{|l|}
$L M-F$ \\
\end{tabular} & $<1$ & 5 & 15 & 33 & 54 & 83 & 7 & 10 & 15 & 266 & 281 & 312 & 40 & 119 & 228 & 1600 & 11825 & 21600 \\
\hline \begin{tabular}{|l|} 
LM-G \\
\end{tabular} & $<1$ & 6 & 18 & 42 & 62 & 97 & 8 & 12 & 17 & 248 & 271 & 318 & 4 & 122 & 214 & 1600 & 8550 & 2410 \\
\hline
\end{tabular}

domínio do nitrogênio na forma de nitrato, devido às boas condições de oxigenação da lagoa. A lagoa não apresentou poluição orgânica, devido às baixas concentrações de nitrogênio amoniacal.
Os resultados das classificações tróficas indicadas pelo Índice de Estado Trófico Modificado, desenvolvido por Toledo Jr. et. al. (1984), determinaram condições mesotróficas em todos os locais da 
Aspectos Qualitativos de Águas de Lagoas Costeiras e seus Fatores Influentes - Estudo de Caso:

Lagoa MÃ̃E-BÁ, Espírito Santo

lagoa Mãe-Bá, exceto nos pontos LM-C e LM-F, que foram classificados como eutróficos. As influências advindas dos esgotos domésticos das comunidades vizinhas possivelmente contribuíram para caracterizar esses locais como eutróficos.

Tabela 5 - Dados de fitoplâncton na lagoa Mãe-Bá - pontos LM-C e LM-F.

\begin{tabular}{|c|c|c|c|}
\hline Data & $\begin{array}{l}\text { Classe do Fito- } \\
\text { plâncton }\end{array}$ & $\begin{array}{c}\text { Concentração } \\
\text { (células/ml) } \\
\text { - Ponto LM-C }\end{array}$ & $\begin{array}{c}\text { Concentração } \\
\text { (células/ml) } \\
\text { - Ponto LM-F }\end{array}$ \\
\hline \multirow[t]{3}{*}{$08 / 01 / 02$} & Cianobactérias & - & 56.270 \\
\hline & Outros Grupos & - & 3.710 \\
\hline & Total & - & 59.980 \\
\hline \multirow[t]{3}{*}{$24 / 01 / 02$} & Cianobactérias & - & 43.364 \\
\hline & Outros Grupos & - & 5.211 \\
\hline & \begin{tabular}{|l|} 
Total \\
\end{tabular} & - & 48.575 \\
\hline \multirow[t]{3}{*}{$07 / 02 / 02$} & Cianobactérias & 54.983 & 48.019 \\
\hline & Outros Grupos & 7.843 & 5.216 \\
\hline & Total & 62.826 & 53.235 \\
\hline \multirow[t]{3}{*}{$30 / 05 / 02$} & Cianobactérias & - & 49.129 \\
\hline & \begin{tabular}{|l} 
Outros Grupos \\
\end{tabular} & - & 8.205 \\
\hline & Total & - & 57.334 \\
\hline \multirow[t]{3}{*}{$18 / 07 / 02$} & Cianobactérias & 88.126 & 85.413 \\
\hline & Outros Grupos & 9.363 & 8.350 \\
\hline & Total & 97.489 & 93.763 \\
\hline \multirow[t]{3}{*}{ 08/08/02 } & Cianobactérias & 73.580 & 69.372 \\
\hline & Outros Grupos & 8.382 & 4.381 \\
\hline & Total & 81.962 & 73.753 \\
\hline \multirow[t]{3}{*}{ 03/09/02 } & Cianobactérias & 96.392 & 64.861 \\
\hline & Outros Grupos & 9.614 & 7.691 \\
\hline & \begin{tabular}{|l|} 
Total \\
\end{tabular} & 106.006 & 72.552 \\
\hline \multirow[t]{3}{*}{$24 / 10 / 02$} & Cianobactérias & 110.258 & 69.573 \\
\hline & Outros Grupos & 12.296 & 7.948 \\
\hline & \begin{tabular}{|l|} 
Total \\
\end{tabular} & 122.554 & 77.521 \\
\hline \multirow[t]{3}{*}{$26 / 11 / 02$} & Cianobactérias & 82.426 & 62.613 \\
\hline & Outros Grupos & 11.032 & 3.805 \\
\hline & Total & 93.458 & 66.418 \\
\hline \multirow[t]{3}{*}{$17 / 12 / 02$} & Cianobactérias & 84.289 & 67.809 \\
\hline & \begin{tabular}{|l|} 
Outros Grupos \\
\end{tabular} & 9.563 & 7.591 \\
\hline & Total & 93.852 & 75.400 \\
\hline
\end{tabular}

A evolução da formação do fitoplâncton na lagoa é um fator importante para a avaliação do processo de eutrofização. Os valores médios encontrados para esse parâmetro nos anos de 2000, 2001 e 2002 foram, respectivamente, $5.578 \mathrm{ind} . / \mathrm{ml}, 8.571$ ind./ml e 16.072 ind./ml em LM-B e 6.169 ind./ml, 10.548 ind./ml e 23.367 ind./ml em LM-E (Limnos, 2003). Dias Jr. e Barroso (1998) encontraram o valor médio de 55.431 ind./ml para o fitoplâncton na lagoa Jacuném, classificada como eutrófica.

Florações de algas constituídas tipicamente por cianobactérias tornam-se dominantes em lagos eutróficos. Essas espécies de algas podem formar espumas superficiais desagradáveis, podem causar mortandade de peixes e prejudicar a qualidade de água de abastecimento (Smith, 2003). Além disso, as cianobactérias têm a característica de produzir toxinas, denominadas cianotoxinas, que podem ser neurotóxicas, hepatotóxicas ou irritantes ao contato. Nos resultados biológicos encontrados na lagoa Mãe-Bá, mostrados na Tabela 5, as algas cianofíceas representaram cerca de $90 \%$ do total do fitoplâncton.

A seguir são apresentadas figuras mostrando os perfis de temperatura, pH, O.D., condutividade elétrica e salinidade monitorados nos sete pontos da lagoa, nas quatro campanhas em 2002.

Os resultados das perfilagens indicaram que a lagoa Mãe-Bá não apresentou estratificação térmica e mostrou perfil de oxigênio dissolvido do tipo ortogrado, principalmente devido às baixas profundidades e ação dos ventos. Comportamento semelhante foi observado nas lagoas costeiras Imboassica, Cabiúnas, Comprida e Carapebus estudadas por Petrucio (1998) e nas lagoas Cacimba, Bonita, Piaba, Piabinha, Parda, do Machado e Zacarias, estudadas por Bozelli et al. (1992). Foram observadas concentrações de O.D. acima da saturação no epilímnio e ao longo da coluna d'água, e concentrações mais baixas no fundo de pontos mais profundos, como o LM-A e LM-E. Essas características são indicativas de ocorrência de processo de eutrofização na lagoa Mãe-Bá.

A lagoa Mãe-Bá apresentou águas ligeiramente salobras, com valores de salinidade próximos ao limite máximo de classificação de águas doces, e valores de condutividade menores que lagoas costeiras fortemente influenciadas pelo mar, como as estudadas por Bozelli et al. (1992), Dias Jr. e Barroso (1998) e Petrucio (1998).

A influência diferenciada do mar em relação aos locais de coleta na lagoa foi observada nos resultados da variável cloretos, que apresentaram pontos homogêneos situados mais distantes do mar. Essa influência foi também verificada nas comparações dos resultados obtidos através das perfilagens, que indicaram que as variáveis O.D., pH, Cond. e Salin apresentaram diferenças significativas com relação ao local de coleta na lagoa $(\mathrm{p}<0,05)$. 

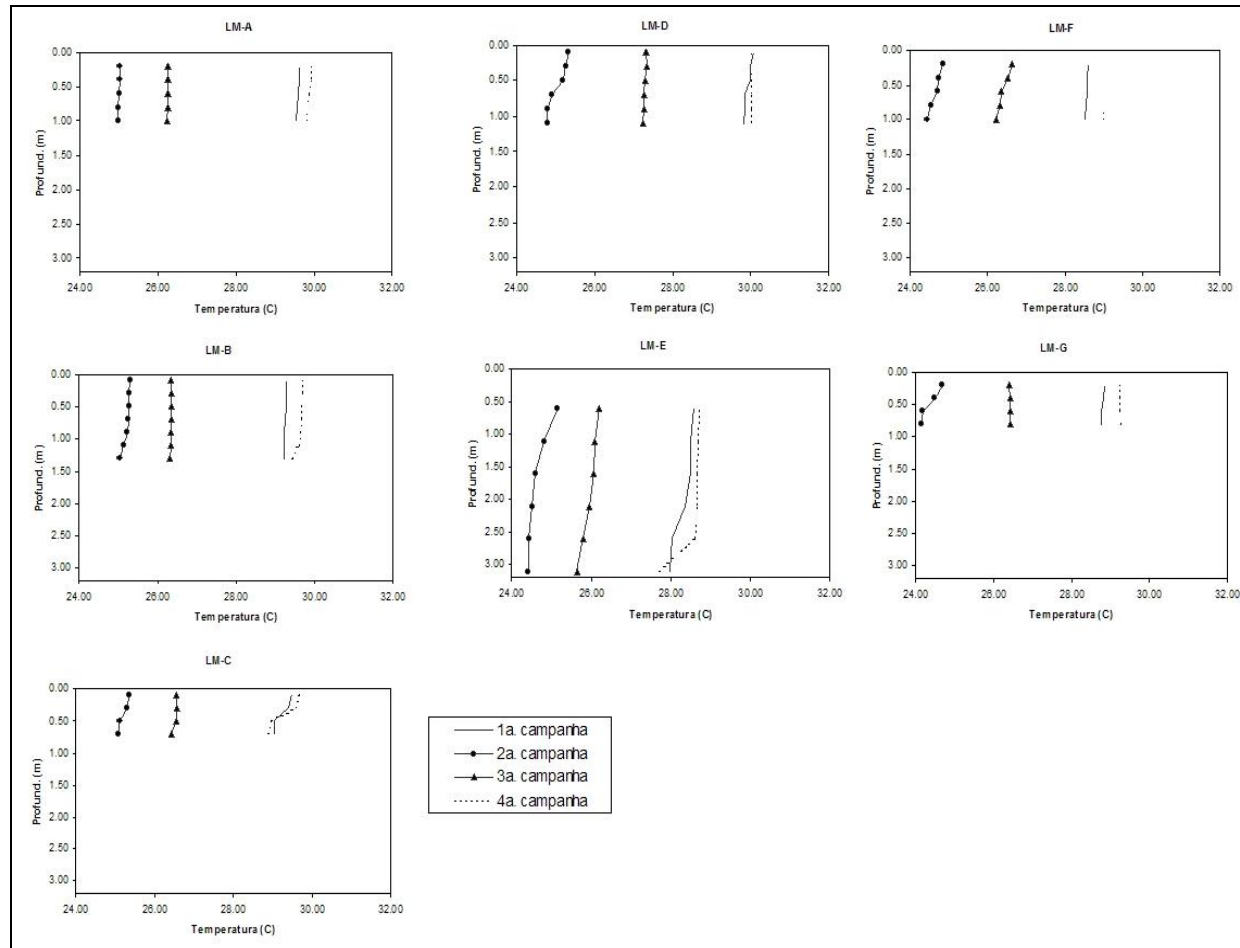

$$
\text { - 1a camparha }
$$

Figura 18 - Variações de T-Água em função da profundidade, de acordo com a campanha e o ponto de coleta na lagoa.
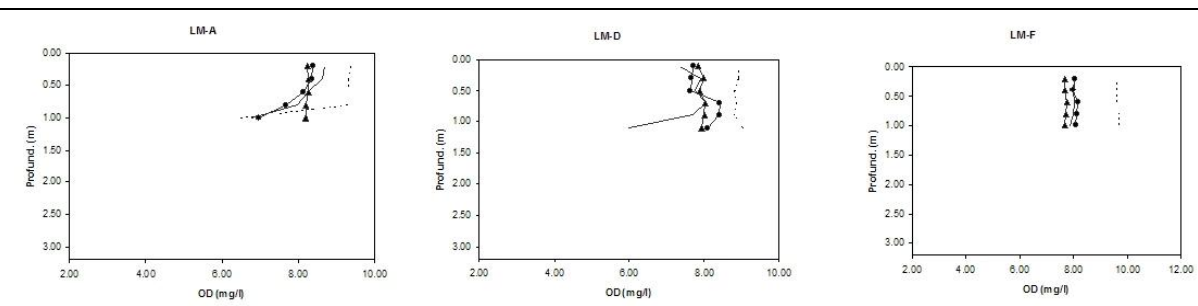

LM-B


\section{- 1a camparha}

- 3 a camparna

. 4a camparna

Figura 19 - Variações de O.D. em função da profundidade, de acordo com a campanha e o ponto de coleta na lagoa. 
Aspectos Qualitativos de Águas de Lagoas Costeiras e seus Fatores Influentes - Estudo de Caso: Lagoa MÃE-BÁ, Espírito Santo

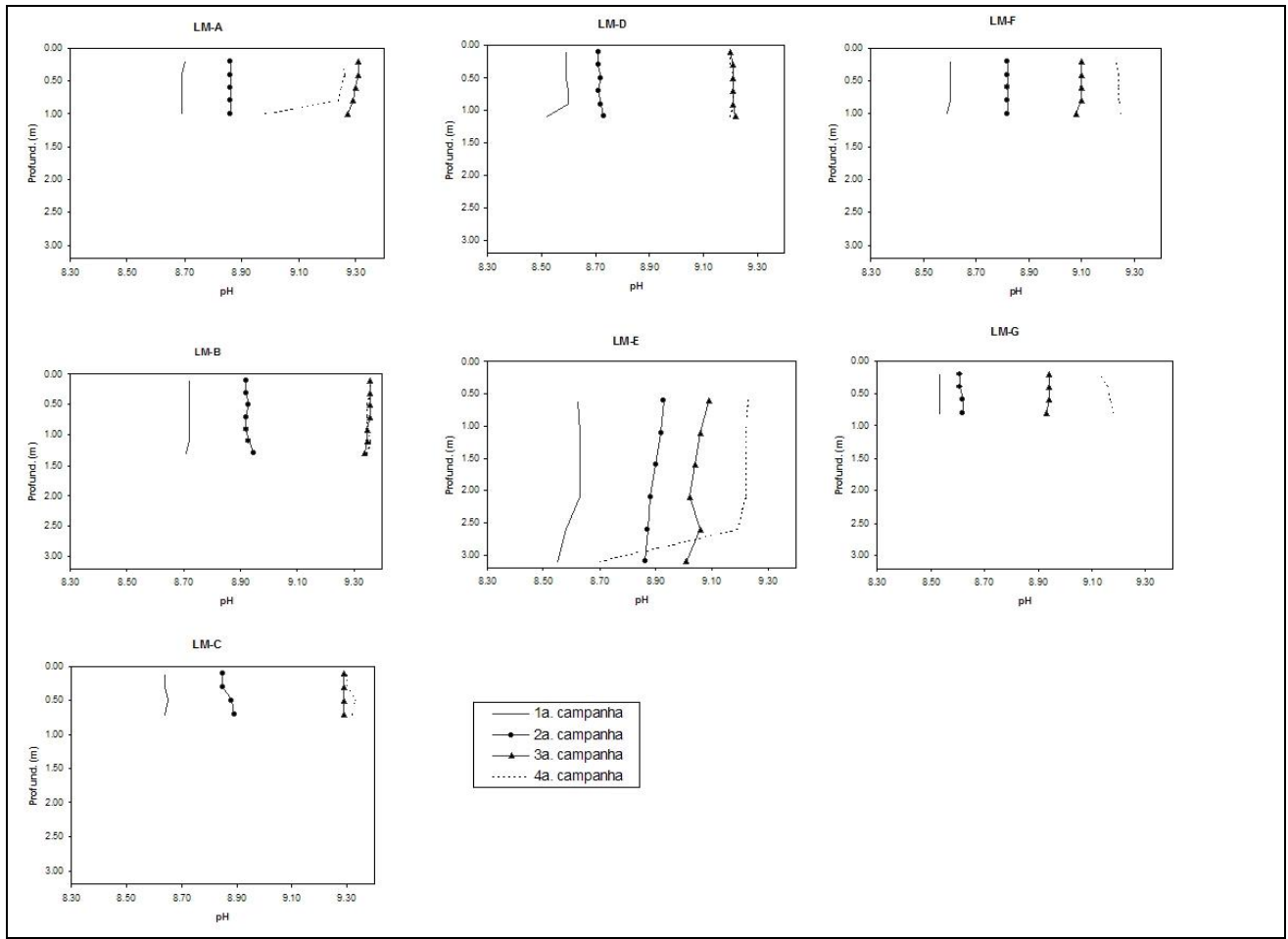

Figura 20 - Variações de pH em função da profundidade, de acordo com a campanha e o ponto de coleta na lagoa.

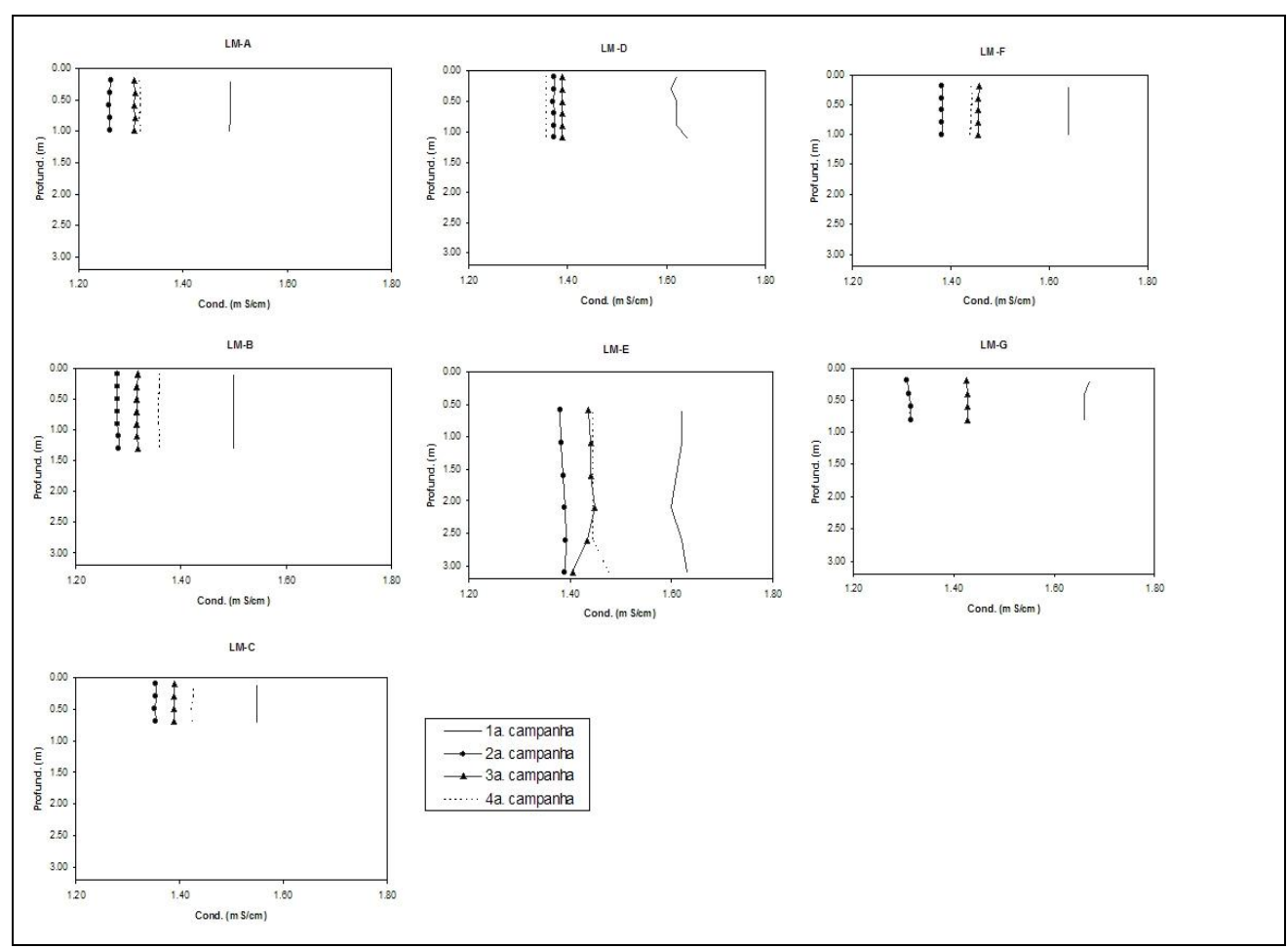

Figura 21 - Variações de Cond. em função da profundidade, de acordo com a campanha e o ponto de coleta na lagoa. 


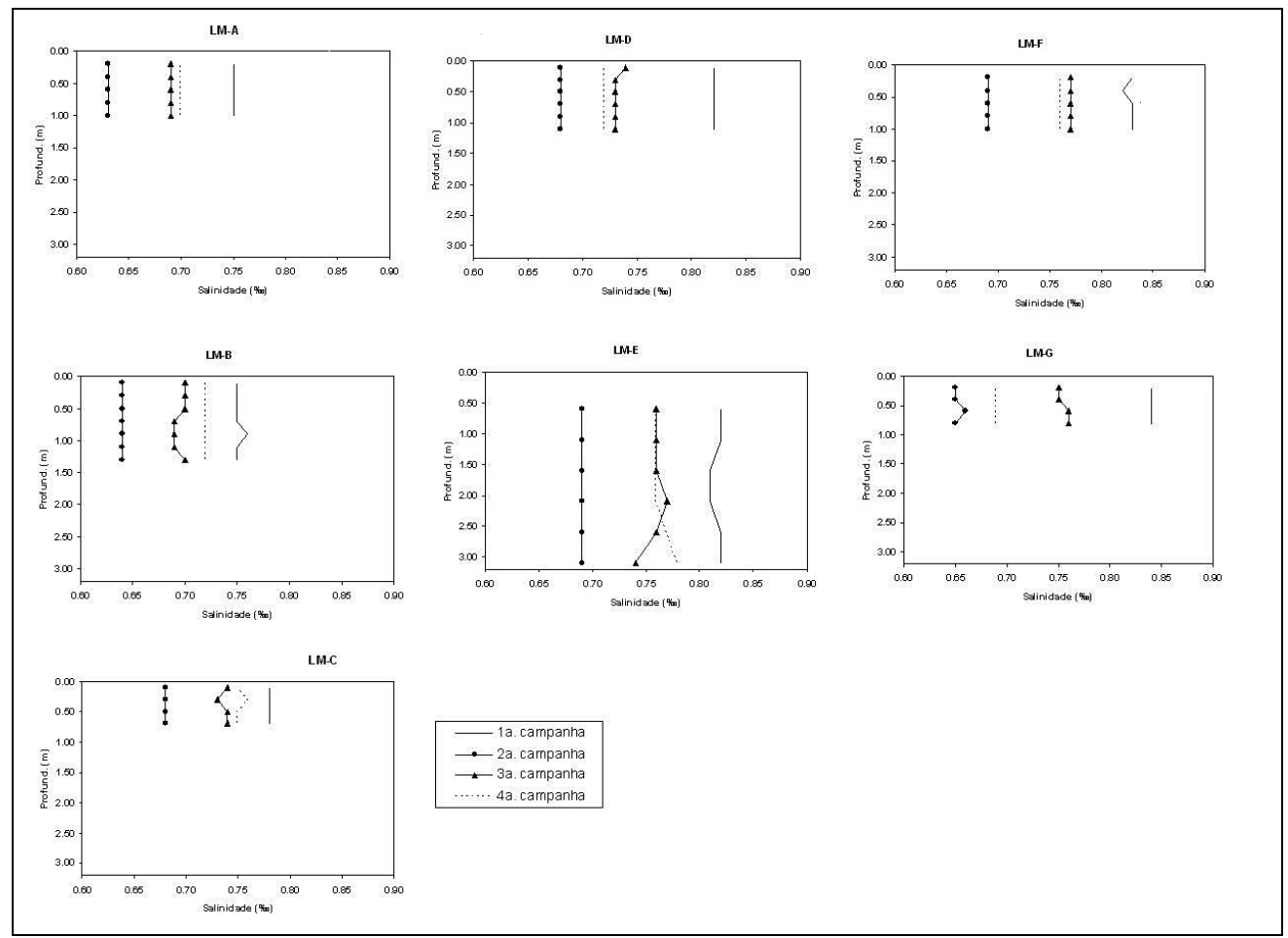

Figura 22 - Variações de Salin. em função da profundidade, de acordo com a campanha e ponto de coleta na lagoa.

\section{CONCLUSÕES}

Através deste estudo foi possível avaliar os resultados decorrentes de influências naturais, relacionadas ao clima da região, e de influências humanas, fortemente interferentes na qualidade da água da lagoa Mãe-Bá, bem como avaliar possíveis interações entre esses fatores.

A comparação dos resultados com os limites estabelecidos pela Resolução CONAMA N. ${ }^{\circ} 20$ de 18 de junho de 1986 mostrou que a lagoa Mãe-Bá apresentou alguns parâmetros não condinzentes com os padrões estabelecidos para águas classe 2 e 7, tais como cor aparente, pH, sólidos dissolvidos, cloretos, demanda bioquímica de oxigênio, fosfato total e ferro solúvel. A Barragem Norte apresentou valores de temperatura da água, $\mathrm{pH}$ e ferro solúvel dentro dos limites estabelecidos para efluentes.

A sazonalidade influenciou a temperatura da água da lagoa Mãe-Bá, que não apresentou estratificação térmica nem química. Ela apresentou águas ligeiramente salobras e valores de condutividade baixos em relação a lagoas costeiras fortemente influenciadas pelo mar. A influência diferenciada do mar em relação aos locais de coleta na lagoa foi observada nos resultados das variáveis cloretos, salinidade e condutividade.

As chuvas atuaram no sentido de aumentar as concentrações de cor aparente, coliformes fecais e coliformes totais na lagoa Mãe-Bá e no sentido de diminuir, pelo efeito de diluição, as concentrações de sólidos dissolvidos, condutividade elétrica, salinidade, cloretos, fósforo total, ferro solúvel e ferro total.

A influência do processo de pelotização refletiu nas concentrações de cor aparente, turbidez e sólidos suspensos na barragem industrial. $\mathrm{O}$ incremento nos sistemas de controle de efluentes domésticos e industriais da usina de pelotização refletiram na diminuição das concentrações de ferro solúvel, ferro total e coliformes fecais na lagoa Mãe-Bá.

$\mathrm{O}$ fósforo mostrou ser o nutriente limitante ao crescimento na lagoa Mãe-Bá. Segundo a metodologia de distribuição de probabilidade de estado trófico baseada em concentrações médias de fósforo total, a lagoa Mãe-Bá foi classificada como mesotrófica no ponto próximo ao lançamento de efluentes industriais e eutrófica no ponto próximo ao lançamento de esgotos domésticos. Os resultados das classificações tróficas indicadas pelo Índice de Estado Trófico Modificado determinaram condições 
Aspectos Qualitativos de Águas de Lagoas Costeiras e seus Fatores Influentes - Estudo de Caso:

Lagoa MÃ̃E-BÁ, Espírito Santo

mesotróficas em todos os locais monitorados na lagoa, exceto nos pontos mais próximos aos lançamentos de esgotos domésticos, que foram classificados como eutróficos.

Supersaturação de oxigênio dissolvido, altos valores de $\mathrm{pH}$ e fósforo total, elevadas diferenças entre os parâmetros cor aparente e real, DQO bruta e filtrada e altas densidades de fitoplâncton, constituídas tipicamente por cianobactérias, indicam a existência de processo de eutrofização na lagoa MãeBá.

\section{REFERÊNCIAS}

APHA. Standard Methods for the Examination of Water and Wastewater, 20a ed. Washington: DC, 1998.

BARNES, R. S. Coastal lagoons. Cambridge, England: Cambridge V. Press, 1980.

BOZELLI, R. L. et al. Padrões de funcionamento das lagoas do baixo Rio Doce: variáveis abióticas e clorofila a (Espírito Santo Brasil). Acta Limnol. Brasil., v. 4, p. 13-31, 1992.

BRASIL. Ministério da Saúde. Portaria no 1.469, de 29 de dezembro de 2000. Lex: coletânia de legislação e jurisprudência. Disponivel em: <http://www.normaambiental.com.br>

DIAS JR., C; BARROSO, G. F. Limnological studies of coastal lagoons in the south of Espírito Santo State (Brazil). Verh. Internat. Verein. Limnol. v. 26, p. 1433-1437, 1998.

ESTEVES, F. A. Fundamentos de limnologia. Rio de Janeiro: Interciência/FINEP, 1988.

LASSERRE, P. Coastal lagoons: sanctuary ecosystems, cradles for culture, targets for economic growth. Nature and Resources (UNESCO), v. 15, n. 4, p. 2-21, 1979.

LIMNOS. Estudo limnológico da Lagoa de Maembá. Relatório Anual 2002. Licença de Operação GAI/No 014/02 da Samarco Mineração S/A. Condicionante 28, 2003.

NIXON, S. W. Nutrient dynamics, primary production and fisheries yields of lagoons. Oceanologica Acta, v. sp., n. 3, p. 357371, 1982.

PETRUCIO, M. M. Caracterização das lagoas Imboassica, Cabiúnas, Comprida e Carapebus a partir da temperatura, salinidade, condutividade, alcalinidade, $\mathrm{O}_{2}$ dissolvido, $\mathrm{pH}$, transparência e material em suspensão. In: ESTEVES, F. A. Ecologia das lagoas costeiras do Parque da Restinga de Jurubatiba e do município de Macaé. Rio de Janeiro, 1998. p. 110122.

SALAS, H; MARTINO, P. A simplified phosphorus trophic state model for warm-water tropical lakes. Water Research, v. 25, n. 3 , p. 341-350, 1991.

SMITH, V.H. Eutrophication of freshwater and coastal marine ecosystems - a global probem. Environ. Sci.\& Pollut. Res., v. 10, n. 1, p. 1-14, 2003.

TOLEDO JR., A. P. et al. Aplicação de modelos simplificados para a avaliação de processo da eutrofização em lagos e reserva- tórios tropicais. In: Congresso Interamericano de Inga. Sanitária y Ambiental, 19., 1984, Santiago. Anais..., Santiago: AIDIS Santiago, 1984, v. 57, 1984.

VOLLENWEIDER, R. A. Eutrophication - A global problem. Water Quality Bulletin, v. 6, p. 59-62, 1981.

\section{Qualitative Aspects of Coastal Lagoon Water and Influencing Factors- Case Study: MÃE-BÁ Lagoon, Espírito Santo.}

\section{ABSTRACT}

Coastal lagoons take up about $13 \%$ of the coasts worldwide. They are shallow, highly productive environments, submitted to continental and marine influences. The multiple uses of their waters and anthropic activities performed in their hydrographic basins have caused major changes in the quality of their water resources. The purpose of using data from Mãe-Bá lagoon, located on the southern coast of the state of Espirito Santo is to contribute to increasing knowledge about the influence of natural and anthropic aspects on water quality parameters of coastal lagoons, and the interactions between the different environmental variables, besides characterizing the degree of productivity of these environments. For this water quality monitoring data from the lagoon, during the period from September 1993 to December 2002, were used for the following parameters: water temperature, real and apparent colors, $p H$, dissolved oxygen, suspended solids, dissolved solids, turbidity, biochemical oxygen demand, chemical oxygen demand, nitrogenated series, total phosphorous, orthophosphates, soluble iron, total iron, fecal coliforms, total coliforms, chlorophyll a, chlorides, conductivity and salinity. Monitoring data on potential industrial effluents and meteorological variables were also surveyed. Statistical tests were performed using the data, at a $5 \%$ level of significance. The results were compared with the limits established by current legislation. Mãe-Bá lagoon presented characteristics common to coastal lagoons in general. Seasonality strongly influenced the temperature of the lagoon water, which did not present thermal stratification and showed a dissolved oxygen profile of the orthograde type, mainly due to the small depths and wind action. The lagoon presents slightly brackish water and lower conductivity values than those of coastal lagoons strongly influenced by the sea. The results of the trophic classifications indicated by the Modified Index of Trophic State and by the methodology for a probability distribution of a trophic state based on total phosphorous concentrations determined eutrophic conditions in the lagoon at points located close to sites where domestic effluents are discharged. Systematic increase of $\mathrm{pH}$ through the years, supersaturation of dis- 
solved oxygen, high values of total phosphorous, differences between the parameters apparent and real color, raw and filtered COD and growth of phytoplankton density, constituted typically by cyanobacteria, indicate the existence of an eutrophication process in Mãe-Bá lagoon.

Key words: coastal lagoons, natural and anthropic influences, water quality, eutrophication. 